\title{
Exploration of candidate serum biomarkers potentially related to the chronic pain condition in Medication-overuse headache
}

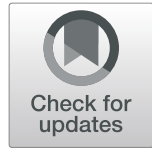

\author{
Lanfranco Pellesi ${ }^{1 *}$ (D, Elisa Bellei ${ }^{2}$, Simona Guerzoni ${ }^{1}$, Maria Michela Cainazzo ${ }^{1}$, Carlo Baraldi ${ }^{1}$, \\ Emanuela Monari ${ }^{2}$ and Luigi Alberto Pini ${ }^{1,3}$
}

\begin{abstract}
Background: Medication Overuse Headache $(\mathrm{MOH})$ is a prevalent and disabling disorder resulting from the overuse of analgesic drugs, triptans or other acute headache medications. In previous proteomic studies, several proteins have been found at high concentrations in the urine of $\mathrm{MOH}$ patients and in the serum of rats with neuropathic pain. The aim of this study was to compare the serum levels of lipocalin-type Prostaglandin D2 synthase (L-PGDS), Vitamin D-binding protein (VDBP), apolipoprotein E (APOE) and apolipoprotein A1 (APOA1) in MOH patients and healthy individuals, further exploring their relationship with cutaneous pain thresholds (CPTs) in the territories innervated by the trigeminal nerve.

Methods: Sixty-nine $\mathrm{MOH}$ patients and 42 age- and sex-matched healthy volunteers were enrolled in the study. Von Frey-like filaments were applied to the skin territories innervated by the trigeminal nerve, to determine the CPTs. L-PGDS, VDBP, APOE and APOA1 were quantified in the serum by Enzyme-linked Immunosorbent Assay (ELISA). Clinical and laboratory data were collected. Comparisons between $\mathrm{MOH}$ patients and healthy individuals were performed using independent $t$ test or $x^{2}$ test. To correlate serum proteins with CPTs, Pearson correlation coefficient or Spearman's rank correlation coefficient were used.

Results: CPTs were lower among MOH patients. L-PGDS, VDBP and APOE had significantly different serum concentrations between groups $(p<0.01)$, but no correlation was found with CPTs. APOA1 serum concentrations did not differ between patients and healthy individuals.

Conclusions: L-PGDS, VDBP and APOE had abnormal serum levels in $\mathrm{MOH}$ patients, confirming their alteration in some conditions of chronic headache and neuropathic pain. However, they had no relationship with CPTs. The indepth study of serum proteins represents a promising approach for a better understanding of $\mathrm{MOH}$, as well as the detection of candidate biomarkers for chronic headache or the risks associated with overuse medications.
\end{abstract}

Keywords: Biomarker, Allodynia, L-PGDS, VDBP, APOE, APOA1, ELISA

\section{Background}

Chronic pain (CP) is a major health care problem. It affects approximately $20 \%$ of the European population [1], and gives considerable costs to the society, more than heart diseases, cancer and diabetes put together [2]. CP is a persistent and disabling pain over a long period, starting from tissue injuries or inflammation, or from

\footnotetext{
* Correspondence: lanfranco.pellesi@gmail.com

${ }^{1}$ Medical Toxicology, Headache and Drug Abuse Centre, University of

Modena and Reggio Emilia, Modena, Italy

Full list of author information is available at the end of the article
}

lesions of the nervous system [3]. The maintenance of pain often aggravates the patient's symptoms, originating the phenomenon of central sensitization, which manifests itself as pain hypersensitivity, allodynia and hyperalgesia [4, 5]. Currently, CP treatment has limited effect because of poor understanding of the mechanisms that lead to the initiation and maintenance; the complete elimination of pain is rarely obtainable. Important reasons for this failure are the high variability of $\mathrm{CP}$ manifestations, as well as the absence of distinctive and measurable biological traits.

(c) The Author(s). 2019 Open Access This article is distributed under the terms of the Creative Commons Attribution 4.0 International License (http://creativecommons.org/licenses/by/4.0/), which permits unrestricted use, distribution, and 
Headaches are prevalent among chronic painful disorders. It is estimated that up to $5 \%$ of the general population suffers from chronic headache, defined as headache occurrence $\geq 15$ days per month [6]. Chronic forms differ from the episodic forms not only in frequency, but also in the lack of effectiveness of most therapies, more medication overuse and lower quality of life [7]. The almost daily intake of acute headache medications can paradoxically worsen the chronic symptoms, leading to a secondary headache named medication-overuse headache $(\mathrm{MOH})$ [8]. $\mathrm{MOH}$ may complicate the majority of primary headaches and it can be caused by several acute headache medications, including migraine-specific (triptans and ergotamine) and nonspecific (nonsteroidal antiinflammatory drugs or NSAIDs, paracetamol, opioids and combinations of analgesics or mixture) drugs. Every class of overused drugs may have a precise causative role, but the repeated intake of the drug does not seem enough to generate $\mathrm{MOH}$. When the acute headache medication is taken regularly for non-headache indications, people without a history of headache do not develop $\mathrm{MOH}[9,10]$. Thus, the association between an individual predisposition and the effects of the headache medications are probably crucial in its outcome [11]. At present, there are no recognisable pathological traits associated with $\mathrm{MOH}$. The only proposed was cutaneous allodynia (CA) [12], defined as pain resulting from an innocuous stimulus to normal skin.

Recently, several urinary proteins have been found at high levels in $\mathrm{MOH}$ patients $[13,14]$. One of the most interesting was lipocalin-type prostaglandin D2 synthase (L-PGDS). The enzyme is responsible for the biosynthesis of prostaglandin D2 (PGD2), the most abundant prostanoid produced in the central nervous system (CNS) [15]. PGD2 is involved in a variety of physiological functions, such as sleep induction, body temperature regulation, vasodilation and pain responses, including allodynia [16-19]. Although the role of LPGDS is not completely defined, the entire prostaglandin system has a central position in pain and central sensitization, resulting in induction of hyperalgesia and CA [20-25]. These findings have been deepened into an animal model of neuropathic pain, revealing an increased expression of L-PGDS as well. Several other proteins were identified in the rat serum 5 weeks after the chronic constriction of sciatic nerve, including Vitamin D-binding protein (VDBP), apolipoprotein E (APOE) and apolipoprotein A1 (APOA1) [26]. Nonetheless, quantitative Polymerase Chain Reaction (qPCR) analysis showed that their transcript levels were overexpressed in the lumbar spinal cord (origin of sciatic nerve), and not in the striatum (an unrelated brain region) [26].

Assuming that some pathophysiological processes may be shared between $\mathrm{MOH}$ and neuropathic pain, the primary objective of this study was to quantify and compare the serum levels of L-PGDS, VDBP, APOE and APOA1, as well as the cutaneous pain thresholds (CPTs) in the territories innervated by the trigeminal nerve in $\mathrm{MOH}$ patients and healthy individuals as control group. Secondarily, serum levels of proteins have been correlated with CPTs in $\mathrm{MOH}$ patients.

\section{Methods \\ Population of the study}

Between September 2016 and January 2018, 69 consecutive $\mathrm{MOH}$ inpatients, referring to the Headache and Drug Abuse Centre at the University of Modena and Reggio Emilia, were enrolled in the study. All patients were diagnosed by trained physicians, according to the International criteria [8]. After signing written informed consent, the collection of demographic data, the measurement of blood pressure and experimental procedures were completed on admittance, before withdrawal treatment was initiated. Patients were tested in the morning, before taking any therapy. A trained investigator performed the CPT tests. The blood and urine routine laboratory tests were performed on the second day of hospitalization, fasting from midnight. For each patient, the subsequent parameters were analysed: (1) prevalent acute headache medication used, classified in triptans, NSAIDs and mixtures (2) daily drug intake (DDI), mean number of acute headache medications consumed every day; (3) years of chronification (CHR), time elapsed since the beginning of chronic symptoms. Prevalent acute headache medication used and DDI were referred to a 3month period before testing.

Forty-two age- and sex-matched healthy volunteers were enrolled as controls. They were recruited from the hospital's medical staff and their relatives. On the experimental day, they also performed blood tests for renal function. Only healthy subjects without migraine and any headache disorders were included in the study, except for tension-type headache for no more than 3 days per month. The daily intake of medicines and the assumption of acute pain medications more than five times in the last month or in the previous $48 \mathrm{~h}$ of the experimental procedures were considered exclusion criteria for the study. For all study participants, exclusion criteria were: headache on admittance to the centre, altered results in routine laboratory tests, other noncephalic chronic painful conditions, and autoimmune, hepatic, renal, oncological, cardiovascular, psychiatric or neurological relevant pathologies.

\section{Serum samples collection and storage}

Venous blood was collected in vacutainer tubes and allowed to clot at room temperature for $1 \mathrm{~h}$. Serum was obtained by centrifugation at $2000 \mathrm{x}$ g for $10 \mathrm{~min}$ at $4{ }^{\circ} \mathrm{C}$; 
a mixture of protease inhibitors (Sigma-Aldrich) was added to prevent protein degradation and alteration. Samples were divided into aliquots and stored at $-80^{\circ} \mathrm{C}$ until analysis.

\section{ELISA test}

Globally, 111 serum samples, which were comprised of 69 $\mathrm{MOH}$ patients and 42 healthy individuals, were analysed by ELISA test. Especially, the expression level of the following proteins was evaluated: L-PGDS (human Prostaglandin D Synthase, Lipocalin-type, ELISA kit, BioVendor, Brno, CZ), VDBP (human Vitamin D-binding protein, ELISA kit, Cusabio Biotech, USA), APOE (human apolipoprotein E, Apo-E, ELISA kit, Cusabio Biotech, USA) and APOA1 (human apolipoprotein A1, Apo-A1, ELISA kit, Cusabio Biotech, USA). The assays were performed according to the manufacturer's protocols and instructions.

L-PGDS and APOA1 assays employ the quantitative sandwich enzyme immunoassay technique, while the VDBP and APOE kits use the competitive inhibition enzyme immunoassay method. Briefly, in the first case, diluted serum samples, standards and blanks were dispensed in the microplate wells containing immobilized pre-coated specific antibody for L-PGDS and APOA1, respectively. After $1 \mathrm{~h}$ incubation, a horseradish peroxidase (HRP)-conjugated antibody specific for L-PGDS and APOA1 was added in each well of the plate, which was incubated further for $1 \mathrm{~h}$. Following a wash to remove any unbound reagent, a substrate solution was added and allowed to react with HRP-conjugate. A blue colour proportional to the amount of sample protein bound in the initial step developed. The reaction was interrupted by an acid solution, which lead to a yellow product. The absorbance was measured at $\lambda 450 \mathrm{~nm}$ in a microplate reader (Multiscan FC, Thermo Scientific, USA). Protein concentrations were calculated from a standard curve generated by the protein stock solution furnished with the kit.

VDBP and APOE kits used a microtiter plate precoated with the respective proteins. Standards and samples $(50 \mu \mathrm{L})$ were added to the plate wells, together with the same amount of HRP-conjugated antibody specific for the protein, and incubated at $37^{\circ} \mathrm{C}$. This step was followed by aspiration and washing repeatedly for five times before adding $90 \mu \mathrm{L}$ of tetramethylbenzidine (TMB) substrate solution to each well (in this case, the colour developed in an opposite way to the amount of protein present in the serum sample). After $10 \mathrm{~min}$ incubation at $37^{\circ} \mathrm{C}$ in the dark, the reaction was interrupted by adding $50 \mu \mathrm{L}$ of stop solution and the colour intensity was measured within $5 \mathrm{~min}$ at $\lambda 450 \mathrm{~nm}$.

\section{Cutaneous pain thresholds}

All the CPTs assessments were performed in absence of a visible headache attack. Calibrated von Frey-like filaments (Touch-Test ${ }^{\oplus}$ Sensory Evaluators filaments, North-Coast Medical Inc., CA) were applied sequentially in scheduled areas, in increasing order for 2 seach to determine the basal CPTs, asking the patient when the touch became a painful or very uncomfortable sting. Assessments were repeated three times and the filaments were used in each location in the following sequence, representing the increased strengths measured in grams (e.g. $0.008 ; 0.02 ; 0.04 ; 0.07 ; 0.16 ; 0.4 ; 0.6 ; 1 ; 1.4 ; 2 ; 4 ; 6 ; 8$; $10 ; 15 ; 26 ; 60 ; 100 ; 180$ and $300 \mathrm{~g})$. The test investigated three cutaneous areas: temple, cheekbone and chin areas (exploring first, second and third division of the trigeminal nerve, respectively), assessed bilaterally in random order. Landmarks definitions were: temple, the skin over the pars orbitalis of frontal and sphenoid bones; cheekbone, the skin over periorbital area of zygomatic bone; chin, the skin of the chin, including the innervation territories of the lower alveolar nerves.

\section{Statistical analysis}

Quantitative variables were expressed as a mean \pm standard deviation. Qualitative variables were expressed as a percentage. Comparison of quantitative variables between $\mathrm{MOH}$ patients and healthy individuals was performed using independent $t$ test, whereas comparison of qualitative variables was performed using $x^{2}$. All $p$-values are two-sided, with a level of significance of $1 \%$. To correlate serum L-PGDS, VDBP, APOE and APOA1 with CPTs, data were analysed with the Pearson correlation coefficient or, if one of the two variables was not normally distributed, Spearman's rank correlation coefficient was used. $\mathrm{R}$ software (version 3.4.3) was used to perform statistical analysis. The level of significance for correlation tests was set at $5 \%$.

\section{Results}

\section{Population characteristics}

We enrolled $69 \mathrm{MOH}$ patients, aged between 27 and 74 years $($ mean $=50.2)$, most of them were females. In more than $90 \%$ of cases, the pre-existing headache disorder was migraine. Tension-type headache was diagnosed as pre-existing headache disorder in three patients, while post-traumatic headache in one patient. On admittance, headache was daily or almost daily for all patients, for not less than 3 months. They assumed about two acute headache medications a day $($ mean $=1.8$, range $=0.33$ 9), and had been suffering of more than 10 years of chronic headache $($ mean $=12.1$, range $=0.33-35$ ). According to the prevalent use of acute headache medications, the majority assumed triptans $(n=48 ; 70 \%)$, fewer patients were taking NSAIDs $(n=10 ; 14 \%)$ or mixture drugs $(n=11 ; 16 \%)$. The latter consisted of a drug containing indomethacin, caffeine and prochlorperazine in $90 \%$ of cases, the remaining ones were codeine plus 
paracetamol. Blood and urine laboratory tests showed no alterations in any parameter, including liver and kidney function. The control group of 42 healthy individuals was an equally female-dominated group, aged between 25 and 76 years $($ mean $=47.0)$. Blood tests performed did not reveal abnormal renal function. Compared to healthy subjects, $\mathrm{MOH}$ patients had higher Zung Self-Rating Depression Scale (ZUNG-D) scores and less prevalent alcohol consumption. No other differences were observed between the two groups. Data and statistical comparisons are summarized in Table 1.

\section{ELISA test}

The level of L-PGDS and APOE was estimated in serum samples collected from $69 \mathrm{MOH}$ patients and 42 healthy participants. Regarding L-PGDS, a significant increase was observed in patients, compared to healthy individuals $(219.2 \mathrm{ng} / \mathrm{ml}$ vs. $188.7 \mathrm{ng} / \mathrm{ml}, p<0.01)$. On the other hand, the serum concentration of APOE was significantly higher in healthy individuals $(72.5 \mu \mathrm{g} / \mathrm{ml}$ vs. $63.9 \mu \mathrm{g} / \mathrm{ml}, p<0.01)$. The level of serum VDBP was estimated in a lower number of samples, i.e., in $57 \mathrm{MOH}$ patients and 31 healthy individuals. This was due to technical problems experienced during the laboratory practice. The control group showed significantly higher levels of serum VDBP $(343.7 \mu \mathrm{g} / \mathrm{ml}$ vs. $289.5 \mu \mathrm{g} / \mathrm{ml}, p<$

Table 1 Demographic, clinical and laboratory data of $\mathrm{MOH}$ patients and healthy individuals

\begin{tabular}{lll}
\hline & MOH patients $(n=69)$ & $\begin{array}{l}\text { Controls } \\
(n=42)\end{array}$ \\
\hline Age, years & $50.2 \pm 9.2$ & $47.0 \pm 13.8$ \\
Sex, female & $90 \%$ & $88 \%$ \\
BMl, kg/m² & $23.7 \pm 4.5$ & $23.7 \pm 3.8$ \\
Coffee & $84 \%$ & $88 \%$ \\
Alcohol & $22 \%^{*}$ & $76 \%$ \\
Cigarettes & $9 \%$ & $12 \%$ \\
SBP, mmHg & $125.9 \pm 12.4$ & $122.1 \pm 13.0$ \\
DBP, mmHg & $79.3 \pm 8.2$ & $76.8 \pm 8.5$ \\
DDI & $1.8 \pm 2.1$ & - \\
CHR & $12.1 \pm 10.3$ & - \\
ZUNG-D & $44.3 \pm 9.5^{* *}$ & $32.3 \pm 7.7$ \\
LDQ & $12.1 \pm 7.4$ & - \\
Creatinine, mg/dl & $0.76 \pm 0.12$ & $0.79 \pm 0.12$ \\
eGFR & $>60 \mathrm{ml} / \mathrm{min}$ & $>60 \mathrm{ml} / \mathrm{min}$ \\
Urea nitrogen, $\mathrm{mg} / \mathrm{dl}$ & $29.4 \pm 7.4$ & $29.6 \pm 8.5$ \\
\hline
\end{tabular}

Data are expressed as mean $\pm \mathrm{SD}$, or in percentage

$B M I$ Body Mass Index; SBP systolic blood pressure; DBP diastolic blood

pressure; DDI daily drug doses; CHR years of chronification; ZUNG-D Zung Self-

Rating Depression Scale; LDQ Leeds Dependence Questionnaire; eGFR

estimated Glomerular Filtration Rate (CKD-EPI Formula)

Statistical significance was evaluated using $X^{2}$ test $\left({ }^{*} p<0.01\right)$ or independent $t$

test $(* * p 0.01)$. Coffee, alcohol and cigarettes users are expressed as a

percentage of occasional and daily users
0.01). Regarding serum APOA1, no differences were found between $57 \mathrm{MOH}$ patients and 30 healthy participants $(49.8 \mu \mathrm{g} / \mathrm{ml}$ vs. $46.9 \mu \mathrm{g} / \mathrm{ml}, p=0.5466)$. Dosages have been performed in fewer samples, due to technical laboratory biases. According to the prevalent acute headache medication used, the concentration of serum proteins was relatively stable. Data regarding the serum concentrations of proteins are summarized in Table 2 and Table 3, as well as better displayed in Fig. 1.

\section{Cutaneous pain thresholds}

According to the absence of any significant difference between right and left sides and the three trigeminal branches, CPTs are presented as an overall average. Compared to healthy participants, mean CPT values in the three tested areas (temples, cheekbone and chin) were significantly lower in $\mathrm{MOH}$ patients $(46.4 \mathrm{~g}$ vs. $96.0 \mathrm{~g}, p<0.01)$. No statistical differences were found between males and females. Data and statistical comparisons are described in Table 2. When the mean CPTs values are compared with the serum concentration of the serum proteins, no relationship is detectable for $\mathrm{L}$ PGDS (Spearman's rank $=-0.001 ; p=0.9921$ ), VDBP (Spearman's rank $=-0.147 ; p=0.4301$ ), APOE (Spearman's rank $=0.053 ; p=0.6667$ ) and APOA1 (Spearman's rank $=0.25769 ; p=0.05296$ ). Graphic correlations are displayed in Fig. 2.

\section{Discussion}

The main findings of this study concern the serum differences of L-PGDS, VDBP and APOE in $\mathrm{MOH}$ patients, compared to healthy individuals. These discrepancies were not one-sided, as L-PGDS was identified at high concentrations, while VDBP and APOE were deficient. Our group of patients with $\mathrm{MOH}$ was nearly aligned with previous case studies [27], confirming to have a higher prevalence of CA than healthy individuals $[12,28]$. Of note, the intake of opioids and drugs containing barbiturates was lower; this might be due to population differences [29] or to the study selection criteria, which excluded patients with other painful syndromes and comorbidities. These assumptions were ideal to correlate the serum concentration of L-PGDS,

Table 2 CPT values and serum proteins levels in healthy individuals and $\mathrm{MOH}$ patients

\begin{tabular}{llll}
\hline & Controls & MOH patients & $P$-value \\
\hline Mean CPT $(\mathrm{g})$ & $96.0 \pm 41.0$ & $46.4 \pm 27.7$ & $<0.00001^{* *}$ \\
L-PGDS $(\mathrm{ng} / \mathrm{ml})$ & $188.7 \pm 39.2$ & $219.2 \pm 58.2$ & $0.0038^{* *}$ \\
VDBP $(\mu \mathrm{g} / \mathrm{ml})$ & $343.7 \pm 95.3$ & $289.5 \pm 88.7$ & $0.0058^{* *}$ \\
APOE $(\mu \mathrm{g} / \mathrm{ml})$ & $72.5 \pm 17.3$ & $63.9 \pm 13.3$ & $0.0042^{* *}$ \\
APOA1 $(\mu \mathrm{g} / \mathrm{ml})$ & $46.9 \pm 17.5$ & $49.8 \pm 23.7$ & $0.546^{\mathrm{NS}}$ \\
\hline
\end{tabular}

CPT values and serum protein concentrations are expressed as mean \pm standard deviation (SD).Independent $t$ test (patients vs. controls): statistical significance ${ }^{* *}: p<0.01,{ }^{\text {NS }}$ : not significant 
Table 3 Serum proteins levels in $\mathrm{MOH}$ patients, according to the prevalent acute headache medication

\begin{tabular}{llll}
\hline & Triptans & NSAIDs & Mixtures \\
\hline L-PGDS $(\mathrm{ng} / \mathrm{ml})$ & $209.4 \pm 57.5$ & $214.9 \pm 53.5$ & $266.0 \pm 44.6$ \\
$\operatorname{VDBP}(\mu \mathrm{g} / \mathrm{ml})$ & $296.0 \pm 86.0$ & $262.3 \pm 67.4$ & $287.8 \pm 124.0$ \\
APOE $(\mu \mathrm{g} / \mathrm{ml})$ & $65.6 \pm 13.2$ & $55.6 \pm 10.7$ & $64.2 \pm 14.2$ \\
APOA1 $(\mu \mathrm{g} / \mathrm{ml})$ & $46.6 \pm 20.3$ & $60.5 \pm 23.0$ & $53.3 \pm 33.3$ \\
\hline
\end{tabular}

Serum protein concentrations are expressed as mean \pm standard deviation (SD)

VDBP and APOE to the pain thresholds measured on the skin of the face. However, none of these proteins (including APOA1) showed any relationship with CPTs.L-PGDS was already found at unusually high concentrations in urine of $\mathrm{MOH}$ patients [13, 14]. The enzyme is highly expressed in leptomeninges [30] and is physiologically eliminated via the kidney. It is of interest for headaches and migraine, as it synthesizes PGD2, a strong vasodilator of the human middle cerebral artery [25], as well as a stimulus for the release of calcitonin gene-related peptide (CGRP) from trigeminal neurons [31]. Alterations in concentration of L-PGDS have also been discussed in other neurological diseases, including cerebral infarction, multiple sclerosis and schizophrenia $[32,33]$. Anyway, its high serum concentration remains unexplained, did not exhibiting any correlation with CA. Another likely explanation behind its high concentration is related to the frequent intake of pain relievers. The common and prolonged assumption of acute headache medications is not uniquely associated with worsening headache, but also to stomach bleeding, liver and kidney damage. NSAIDs use was associated with a 3-fold greater risk for acute renal failure compared with non-NSAIDs use; this risk was dose-dependent and increased with long-term use [34]. About triptans, their potential kidney injury is less known, although some cases of renal infarction have been reported after prolonged use [35]. By adding that L-PGDS accumulates in the serum of patients with impaired renal function, especially in dialysis patients (ca. 100-fold), and it has been proposed in the past as a diagnostic marker for early renal injury $[36,37]$, the renal impairment may be a valid argument for its elevated levels. However, the renal function indicators in the blood of $\mathrm{MOH}$ patients were not different from those of healthy volunteers.

Serum concentrations of VDBP and APOE were higher in healthy individuals. VDBP is primarily a carrier and transporter of vitamin D in the circulation. It also is a component of the extracellular actin-scavenger system, comprising gelsolin; specifically, VDBP binds and facilitates clearance of monomeric actin, released upon injury [38]. Furthermore, VDBP works as a macrophageactivating factor (MAF), initiating macrophage activity [39]. The current result contradicts the findings in rats, where the serum level of VDBP was elevated up to 5 weeks, after the chronic constriction injury of the sciatic nerve [26]. However, this agrees with other human studies which investigated its role in chronic painful conditions. With a methodological approach like the one we adopted, serum VDBP was identified among the downregulated spots in carpal tunnel syndrome patients, compared to healthy individuals [40]. Moreover, a Japanese family study identified a possible dysfunction of VDBP in migraineurs [41]. It has been assumed that a lower binding of the VDBP to monocyte chemoattractant protein-1 (MCP-1), a member of the monocyte chemoattractant protein family, may be involved in the development of migraine pain. Elevated CSF levels of MCP-1 were already reported in migraine patients [42] and the chemokine can also trigger CGRP release [43]. Regarding vitamin $\mathrm{D}$, the natural ligand of VDBP, more data are available. It has been associated with the aetiology and persistence of painful conditions [44], and its supplementation can relieve pain in most patients with a vitamin D deficiency [45]. Interestingly, vitamin D inadequacy has been linked to higher doses of analgesics among patients with chronic musculoskeletal pain [46], In migraine patients, serum vitamin D and Vitamin D receptor levels were found to be lower than in controls, whereas serum VDBP levels were similar between the two groups [47]. In this study, Vitamin D was not dosed. In the future, interesting advancements in $\mathrm{MOH}$ could concern the dosage of vitamin D and MCP-1, together with a re-evaluation of the VDBP protein.

More concealed is the association between APOE and pain regulation processes [48]. It transports cholesterol into the blood and has many essential functions in the brain, including synaptogenesis, regulating synaptic transmission and promoting nerve regeneration after a nerve injury [49]. Despite intriguing reasons that favour the association between APOE and pain, few human studies were conducted to date. In relation to headache conditions, APOE-2 allele has been identified as a risk factor for migraine, whereas APOE $\varepsilon 4$ allele is positively related to headache, including migraine and tension-type headache [50, 51]. Yet, further research is required for the reason behind the low serum concentration of APOE in patients with $\mathrm{MOH}$.

The study has some limitations. First, our patients were mainly represented by women, but an evaluation of the serum proteins in the light of the hormonal state is lacking. And, the association between these proteins and the overuse medication has not been studied exhaustively. The association between proteins and pain might be missing because the protein markers are possibly deregulated from the pain state. Presumably, such alterations are not directly related to the central pain sensitization, rather to other aspects of chronic headache or the excessive intake of acute headache medications, e.g. the decrease of VDBP and APOE could indicate liver 

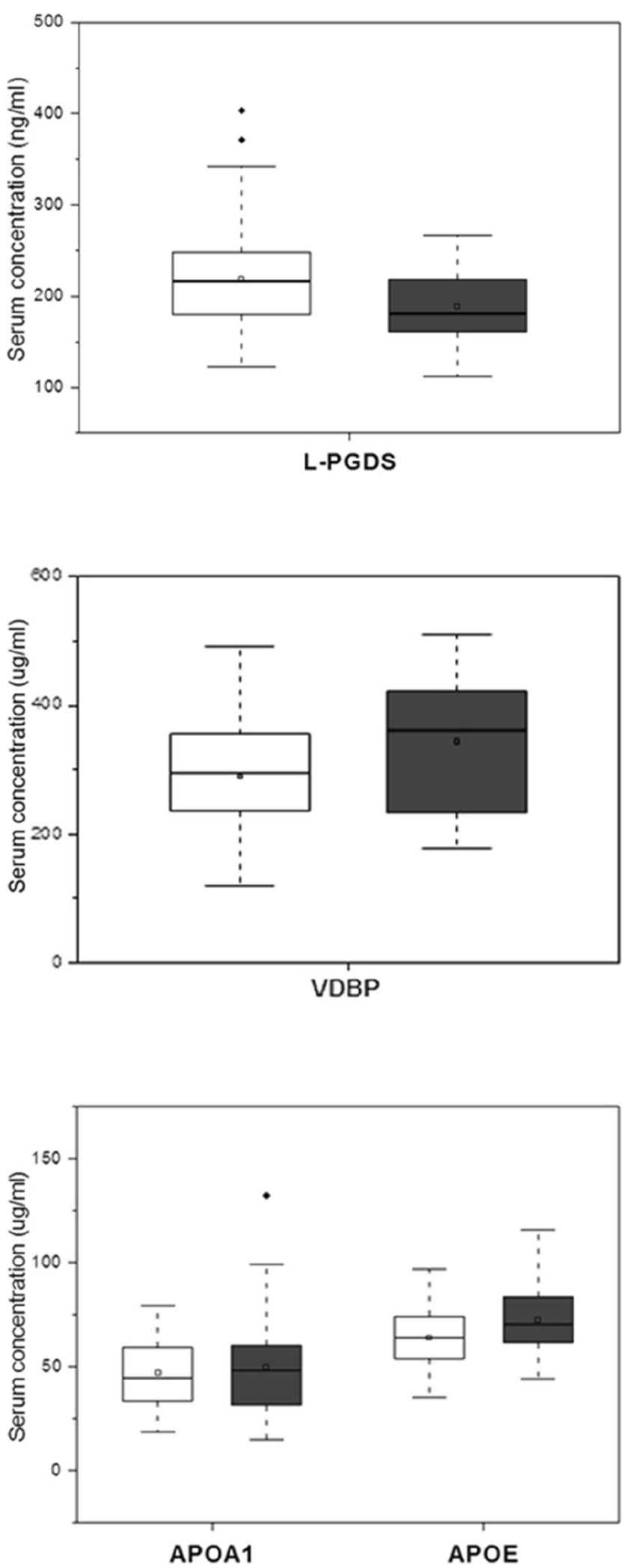

Fig. 1 Box plots of serum concentrations of L-PGDS, VDBP and apolipoproteins in MOH patients (white) and healthy individuals (grey) 

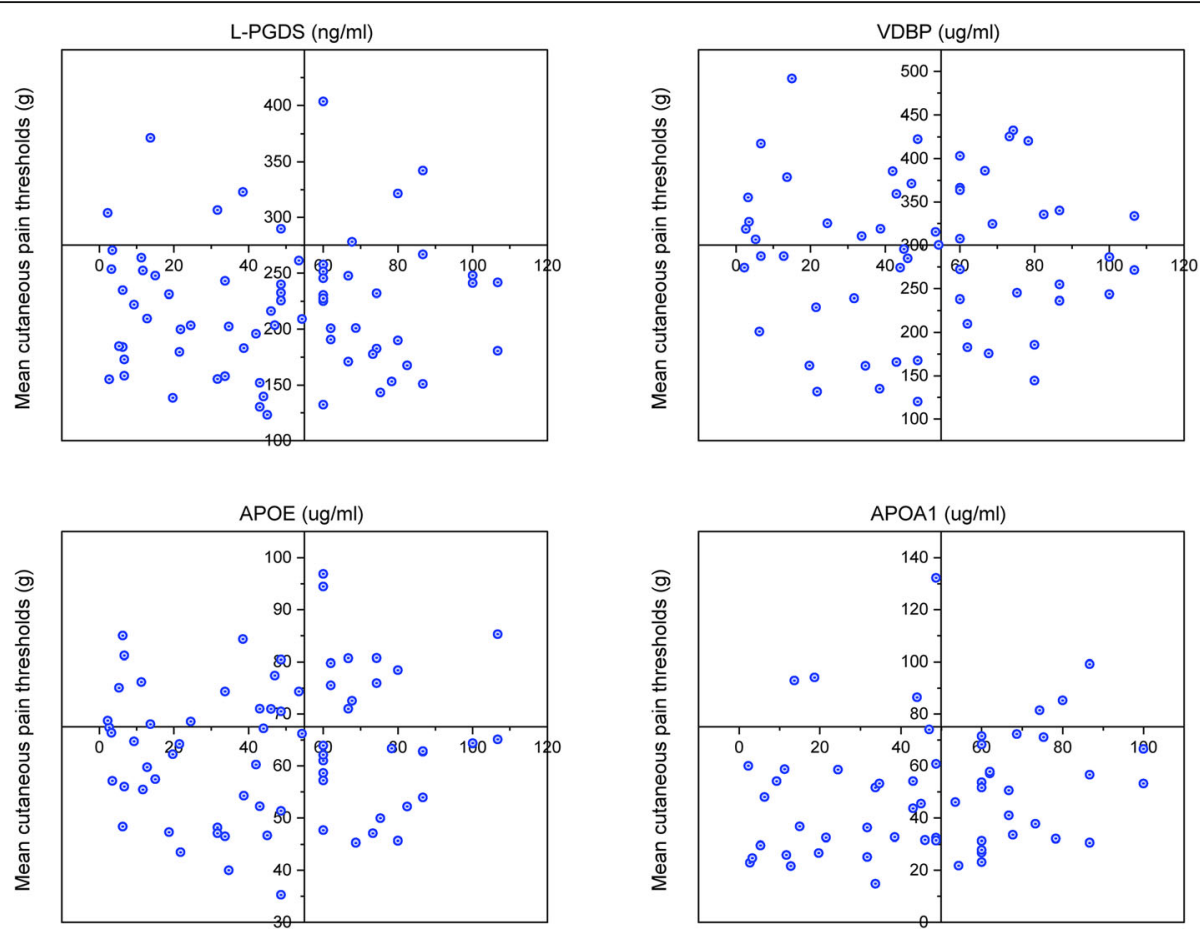

Fig. 2 Relationship between mean CPT values and serum concentration of target proteins

stress due to excessive medication intake. Anyway, the liver function of $\mathrm{MOH}$ patients evaluated at the admission to the hospital were not abnormal. Alternatively, these proteins might actually be related to some aspect of the chronic pain condition, but CPTs might function only as a proxy for the medication overuse. In order to understand whether medication overuse affect the serum proteins, it would be interesting to study how these drugs change in the light of improvements due to medication withdrawal or prophylactic therapies. Several biomarkers were already investigated in $\mathrm{MOH}$, including genetic polymorphisms and neuroimaging abnormalities [52], however the exploration of serum biomarkers remain more attractive and desirable, having the appeal of not be affected by the patient's hydration status and urine flow rate, as well as being easily measurable and suitable for follow-up.

\section{Conclusions}

In conclusion, this study has demonstrated differences in the concentration of distinct serum proteins between $\mathrm{MOH}$ patients and healthy individuals. However, none of them appear to be involved in facial allodynia, one of the most distinctive aspect of $\mathrm{MOH}$ patients. Presumably, such alterations are not related to the central sensitization, rather to the excessive intake of acute headache medications. It would now be interesting to study these markers and their role in medication overuse, correlating their progress after a medication withdrawal or the start of prophylaxys therapy. In the future, it would be also of interest to explore the levels of drugs (e.g., triptans, NSAIDs, paracetamol, ...) and correlate them with the protein markers and/or other clinical aspects of $\mathrm{MOH}$.

\section{Abbreviations}

APOA1: Apolipoprotein A1; APOE: Apolipoprotein E; CA: Cutaneous allodynia; CGRP: Calcitonin gene-related peptide; CHR: Years of chronification; CNS: Central nervous system; CP: Chronic pain; CPTs: Cutaneous pain thresholds; CZ: Czech Republic; DDI: Daily drug intake; ELISA: Enzyme-linked Immunosorbent Assay; HRP: Horseradish peroxidase; L-PGDS: Lipocalin-type Prostaglandin D2 synthase; MAF: Macrophage-activating factor; MCP-

1: Monocyte chemoattractant protein-1; $\mathrm{MOH}$ : Medication Overuse

Headache; NSAIDs: Nonsteroidal anti-inflammatory drugs;

PGD2: Prostaglandin D2; qPCR: Quantitative Polymerase Chain Reaction;

TMB: Tetramethylbenzidine; USA: United States; VDBP: Vitamin D-binding protein; ZUNG-D: Zung Self-Rating Depression Scale

\section{Acknowledgments}

The authors would like to thank Ms. Elizabeth Frances Jephcote for her assistance in writing the manuscript.

\section{Authors' contributions}

LP conceived the study, recruited patients and healthy volunteers, collected data, conducted the CPT tests, performed the statistical analysis and drafted the manuscript. EB and EM conceived the study, performed ELISA tests and drafted the manuscript. SG, MMC and CB recruited patients and healthy volunteers, participated in the coordination of the study and revised the manuscript. LAP conceived the study, supervised the work, participated in its design and coordination and drafted the manuscript. All authors read and approved the final version of the manuscript.

Funding

The authors received no specific funding for this study. 


\section{Availability of data and materials}

All relevant data are within the paper. The datasets used and/or analysed during the current study are available from the corresponding author on reasonable request.

\section{Ethics approval and consent to participate}

This study was performed following the Helsinki Declaration principles, approved by the local Ethical Committee of Modena (prot. 2073) and subsequently amended by the Area Vasta Emilia Nord Ethics Committee (prot. 0019446/18). All patients and healthy volunteers gave their written consent to participate in the study before any experimental procedure was performed.

\section{Consent for publication}

Not applicable.

\section{Competing interests}

The authors declare that they have no competing interests.

\section{Author details}

${ }^{1}$ Medical Toxicology, Headache and Drug Abuse Centre, University of Modena and Reggio Emilia, Modena, Italy. ${ }^{2}$ Department of Diagnostic Medicine, Clinic and Public Health, Proteomic Lab, University of Modena and Reggio Emilia, Modena, Italy. ${ }^{3}$ Center for Neuroscience and Neurotechnology, University of Modena and Reggio Emilia, Modena, Italy.

\section{Received: 22 February 2019 Accepted: 20 September 2019}

Published online: 17 October 2019

\section{References}

1. van Hecke O, Torrance N, Smith BH. Chronic pain epidemiology and its clinical relevance. Br J Anaesth. 2013;111:13-8.

2. Gaskin DJ, Richard P. The economic costs of pain in the United States. J Pain. 2012:13:715-24.

3. Pallen CJ. Breaking the pain connection. Nat Med. 2008;14:1313-5.

4. Woolf CJ. Central sensitization: implications for the diagnosis and treatment of pain. Pain. 2011;153:S2-S15.

5. Latremoliere A, Woolf CJ. Central sensitization: a generator of pain hypersensitivity by central neural plasticity. J Pain. 2009;10:895-926.

6. Stovner LJ, Zwart JA, Hagen K, Terwindt GM, Pascual J. Epidemiology of headache in Europe. Eur J Neurol. 2006;13:333-45.

7. Jensen R, Rasmussen BK. Burden of headache. Expert Rev Pharmacoecon Outcomes Res. 2004:4:353-9.

8. Headache Classification Committee of the International Headache Society. The international classification of headache disorders, 3rd edition (beta version). Cephalalgia. 2013;33:629-808.

9. Bahra A, Walsh M, Menon S, Goadsby PJ. Does chronic daily headache arise de novo in association with regular use of analgesics? Headache. 2003;43:179-90.

10. Wilkinson SM, Becker WJ, Heine JA. Opiate use to control bowel motility may induce chronic daily headache in patients with migraine. Headache. 2001:41:303-9.

11. De Felice M, Ossipov MH, Porreca F. Persistent medication-induced neural adaptations, descending facilitation, and medication overuse headache. Curr Opin Neurol. 2011:24:193-6.

12. Bigal ME, Ashina S, Burstein R, Reed ML, Buse D, Serrano D, Lipton RB, AMPP group. Prevalence and characteristics of allodynia in headache sufferers: a population study. Neurology. 2008;70:1525-33.

13. Bellei E, Monari E, Cuoghi A, Bergamini S, Guerzoni S, Ciccarese M, Ozben T, Tomasi A, Pini LA. Discovery by a proteomic approach of possible early biomarkers of drug-induced nephrotoxicity in medication-overuse headache. J Headache Pain. 2013;14:6.

14. Bellei E, Monari E, Bergamini S, Cuoghi A, Tomasi A, Guerzoni S, Ciccarese M, Pini LA. Validation of potential candidate biomarkers of drug-induced nephrotoxicity and allodynia in medication-overuse headache. J Headache Pain. 2015;16:77.

15. Narumiya S, Ogorochi T, Nakao K, Hayaishi O. Prostaglandin D2 in rat brain, spinal cord and pituitary: basal level and regional distribution. Life Sci. 1982; 31:2093-103.

16. Ito S, Narumiya S, Hayaishi O. Prostaglandin D2: a biochemical perspective. Prostaglandins Leukotrienes Essent Fatty Acids. 1989;37:219-34.
17. Hayaishi O. Molecular mechanisms of sleep-wake regulation: roles of prostaglandins D2 and E. FASEB J. 1991;5:2575-81.

18. Urade $Y$, Hayaishi $O$, Matsumura H, Watanabe K. Molecular mechanism of sleep regulation by prostaglandin D2. J Lipid Mediat Cell Signal. 1996;14:71-82.

19. Eguchi N, Minami T, Shirafuji N, Kanaoka Y, Tanaka T, Nagata A, Yoshida $\mathrm{N}$, Urade $\mathrm{Y}$, Ito $\mathrm{S}$, Hayaishi O. Lack of tactile pain (allodynia) in lipocalintype prostaglandin D synthase-deficient mice. Proc Natl Acad Sci U S A. 1999:96:726-30

20. Ito S, Okuda-Ashitaka E, Minami T. Central and peripheral roles of prostaglandins in pain and their interactions with novel neuropeptides nociceptin and nocistatin. Neurosci Res. 2001:41:299-332.

21. Kawabata A. Prostaglandin E2 and pain - an update. Biol Pharm Bull. 2011; 34:1170-3.

22. Wienecke T, Olesen J, Oturai PS, Ashina M. Prostacyclin (epoprostenol) induces headache in healthy subject. Pain. 2008;139:106-16.

23. Wienecke T, Olesen J, Oturai PS, Ashina M. Prostaglandin E2 (PGE2) induces headache in healthy subjects. Cephalalgia. 2009;29:509-19.

24. Wienecke T, Olesen J, Ashina M. Prostaglandin 12 (epoprostenol) triggers migraine like attacks in migraineurs. Cephalalgia. 2010;30:179-90.

25. Wienecke T, Olesen J, Ashina M. Discrepancy between strong cephalic arterial dilatation and mild headache caused by prostaglandin D2 (PGD2). Cephalalgia. 2011;31:65-76

26. Bellei E, Vilella A, Monari E, Bergamini S, Tomasi A, Cuoghi A, Guerzoni $S$, Manca L, Zoli M, Pini LA. Serum protein changes in a rat model of chronic pain show a correlation between animal and humans. Sci Rep. 2017;7:41723.

27. Bigal ME, Borucho S, Serrano D, Lipton RB. The acute treatment of episodic and chronic migraine in the USA. Cephalalgia. 2009;29:891-7.

28. Zappaterra M, Guerzoni S, Cainazzo MM, Ferrari A, Pini LA. Basal cutaneous pain threshold in headache patients. J Headache Pain. 2011;12:303-10.

29. Peters M, Abu-Saad HH, Robbins I, Vydelingum V, Dowson A, Murphy M. Patients' management of migraine and chronic daily headache: a study of the members of the migraine action association (United Kingdom). Headache. 2005:45:571-81.

30. Sekeroglu A, Jacobsen JM, Jansen-Olesen I, Gupta S, Sheykhzade M, Olesen 1, Bhatt DK. Effect of PGD2 on middle meningeal artery and mRNA expression profile of L-PGD2 synthase and DP receptors in trigeminovascular system and other pain processing structures in rat brain. Pharmacol Rep. 2017;69:50-6.

31. Jenkins DW, Feniuk W, Humphrey PPA. Characterization of the prostanoid receptor types involved in mediating calcitonin gene-related peptide release from cultured rat trigeminal neurones. $\mathrm{Br} J$ Pharmacol. $2001 \cdot 134: 1296-302$

32. Harrington MG, Aebersold R, Martin BM, Merril CR, Hood L. Identification of a brain-specific human cerebrospinal fluid glycoprotein, beta-trace protein. Appl Theor Electrophor. 1993;3:229-34.

33. Hiraoka A, Miura I, Hattori M, Tominaga L, Machida S. Capillary-zone electrophoretic analyses of the proteins and amino acid components in cerebrospinal fluid of central nervous system diseases. Biol Pharm Bull. 1993;16:949-52.

34. Huerta C, Castellsague J, Varas-Lorenzo C, García Rodríguez LA. Nonsteroida anti-inflammatory drugs and risk for ARF in the general population. Am J Kidney Dis. 2005:45:531-9.

35. Abramovitz B, Leonberg-Yoo A, Bahrainwala JZ, Litt H, Rudnick MR. Bilateral renal infarctions during the use of sumatriptan. Kidney Int Rep. 2018;3:1233-6.

36. Hoffmann A, Nimtz M, Conradt HS. Molecular characterization of $\beta$-trace protein in human serum and urine: a potential diagnostic marker for renal diseases. Glycobiology. 1997;7:499-506.

37. Maesaka JK, Palaia T, Fishbane S, Ragolia L. Contribution of prostaglandin D2 synthase to progression of renal failure and dialysis dementia. Semin Nephrol. 2002;22:407-14

38. Van Baelen H, Bouillon R, De Moor P. Vitamin D-binding protein (Gcglobulin) binds actin. J Biol Chem. 1980;255:2270-2.

39. Yamamoto N, Kumashiro R. Conversion of vitamin D3 binding protein (group-specific component) to a macrophage activating factor by the stepwise action of beta-galactosidase of B cells and sialidase of T cells. J Immunol. 1993:151:2794-802.

40. Oh YM, Ma TZ, Kwak YG, Eun JP. Proteomic evaluation to identify biomarkers for carpal tunnel syndrome: a comparative serum analysis. Connect Tissue Res. 2013;54:76-81.

41. Nagata E, Fujii N, Hosomichi K, Mitsunaga S, Suzuki Y, Mashimo $Y$, Tsukamoto H, Satoh T, Osawa M, Inoue I, Hata A, Takizawa S. Possible 
association between dysfunction of vitamin D binding protein (GC globulin) and migraine attacks. PLoS One. 2014;9:e105319.

42. Bø SH, Davidsen EM, Gulbrandsen P, Dietrichs E, Bovim G, Stovner L, White LR. Cerebrospinal fluid cytokine levels in migraine, tension-type headache and cervicogenic headache. Cephalalgia. 2009;29:365-72.

43. Qin X, Wan Y, Wang X. CCL2 and CXCL1 trigger calcitonin gene-related peptide release by exciting primary nociceptive neurons. J Neurosci Res. 2005:82:51-62.

44. Shipton EE, Shipton EA. Vitamin D deficiency and pain: clinical evidence of low levels of vitamin $D$ and supplementation in chronic pain states. Pain Ther. 2015:4:67-87.

45. Abbasi M, Hashemipour S, Hajmanuchehri F, Kazemifar M. Is vitamin D deficiency associated with non specific musculoskeletal pain? Glob Health J Sci. 2013;5:107-11.

46. Turner MK, Hooten WM, Schmidt JE, Kerkvliet JL, Townsend CO, Bruce BK. Prevalence and clinical correlates of vitamin D inadequacy among patients with chronic pain. Pain Med. 2008;9:979-84.

47. Celikbilek A, Gocmen AY, Zararsiz G, Tanik N, Ak H, Borekci E, Delibas N. Serum levels of vitamin $D$, vitamin D-binding protein and vitamin D receptor in migraine patients from Central Anatolia region. Int I Clin Pract. 2014;68:1272-7.

48. Dhillon $\mathrm{H}$, Singh $\mathrm{S}$. Role of apolipoprotein $\mathrm{E}$ in the tangled mystery of pain. Med Hypotheses. 2018;114:58-64

49. Melemedjian OK, Yassine HN, Shy A, Price TJ. Proteomic and functiona annotation analysis of injured peripheral nerves reveal ApoE as a protein upregulated by injury that is modulated by metformin treatment. Mol Pain. 2013;9:14.

50. Gupta R, Kumar V, Luthra K, Banerjee B, Bathia MS. Polymorphism in apolipoprotein $\mathrm{E}$ among migraineurs and tension-type headache subjects. J Headache Pain. 2009;10:115-20.

51. Miao J, Wang F, Zheng W, Zhuang X. Association of the Apolipoprotein E polymorphism with migraine: a meta-analysis. BMC Neurol. 2015;15:138.

52. Diener HC, Holle D, Solbach K, Gaul C. Medication-overuse headache: risk factors, pathophysiology and management. Nat Rev Neurol. 2016;12:575-83.

\section{Publisher's Note}

Springer Nature remains neutral with regard to jurisdictional claims in published maps and institutional affiliations.

Ready to submit your research? Choose BMC and benefit from:

- fast, convenient online submission

- thorough peer review by experienced researchers in your field

- rapid publication on acceptance

- support for research data, including large and complex data types

- gold Open Access which fosters wider collaboration and increased citations

- maximum visibility for your research: over $100 \mathrm{M}$ website views per year

At $\mathrm{BMC}$, research is always in progress.

Learn more biomedcentral.com/submissions 